\title{
Unique stroke-multiplicity of positive lightning in Malaysia
}

\begin{abstract}
This paper presents the unique characteristics of positive lightning generated vertical electric field waveforms recorded in Malaysia. The focus of the study was the waveforms due to positive lightning and their number of return strokes in a flash. A total of 172 lightning ground flash records were analysed, out of which 57 flashes contained positive lightning with a number of them having high numbers of subsequent return strokes which is somewhat unusual with observations elsewhere. The field measurements were done by using a parallel plate antenna coupled with a recording system. In contrary to the majority of positive lightning return strokes that has been recorded previously, where the average multiplicity is one, this study showed an average multiplicity of 3.86 which is almost four times higher than that is usually observed.
\end{abstract}

Keyword: Electric field; Positive lightning; Return stroke; Stroke-multiplicity 